\title{
Chile urbano: La ciudad en la literatura y el cine de Magda Sepúlveda
}

Santiago: Cuarto Propio, 2013, 330 páginas.

NAÍn NómeZ

Universidad de Santiago de Chile.

Santiago, Chile

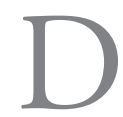
espués de leer la introducción de la editora, me doy cuenta que probablemente este estudio multidisciplinario no necesita otra presentación. En ella, Magda Sepúlveda ordena los artículos a partir de la pregunta: ¿qué puebla la imaginación del espacio de Chile? Creo que mucho más se refiere a preguntarse qué puebla el espacio imaginario de Santiago, ya que ciudad es preferentemente ésta y el imaginario urbano con sus obvias excepciones se focaliza en la capital.

La presentadora del libro Chile urbano logra hacer una ordenación segmentada de la totalidad y de cada uno de los trabajos, trenzándolos, hilándolos y dándole consistencia a una serie de ponencias que sin el orden del libro y sin este prólogo, perderían su articulación y su sentido común. El diálogo que produce el prólogo con los textos es fructífero y proyectivo y le da una consistencia que de otro modo naufragaría en la heterogeneidad. De esta manera, desde su entrada conectiva de filiación/separación con los monumentos de la Plaza de Armas como dualidad y superposición de culturas, su escrito va mostrando el recorrido que hacen los otros trabajos, como si fuera una ruta espacial y temporal que con los consabidos puntos de fuga, darán cuenta de un recorrido por nuestra urbanidad imaginada (pero también real), que parece siempre volver al mismo lugar.

Así es como esta entrada mencionada se abre al primer capítulo titulado "Entrada prohibida: segregaciones espaciales", que alude a las restricciones impuestas por las elites de los siglos XIX y XX y las segregaciones que continúan en el XXI. Aquí Magda Sepúlveda estructura los trabajos de Roberto Hozven, Cristián Opazo y Juan Poblete. En el primero, "Altibajos de la sociabilidad en ensayos chilenos", se muestra la contradicción entre la 
manera como son recreadas las ciudades chilenas en la literatura (progreso económico y cultural de la nación) frente a la crítica de los ensayistas que las muestran como signo de anarquía, caudillismo y patrimonio privado, como simulacro de orden. El autor cita a autores de diferentes épocas como es el caso de Bilbao, Alfredo Jocelyn Holt, Richard Morse, Luis Oyarzún, Domingo Melfi y finalmente nuestro cronista dominical Carlos Peña. En otro tono, podemos oponer las visiones de Cristián Opazo y Juan Poblete. Ambos aluden a segregaciones recientes de los años noventa en el periodo de la así llamada transición a la democracia. Opazo en su texto "Junk Food: lectura sentimental de Fuguet", trabaja a partir del libro Sobredosis de Fuguet, los cambios tecnológicos que se avisoran en el Chile del, a medios destape, que a su juicio aparecen en el texto como una ambivalencia cultural que permite flexibilizar los mecanismos de censura. Si bien es cierto, como señala el autor, que el libro muestra un segmento de la población que se alimenta de los residuos de la globalización y de un consumismo análogo al que vivimos hoy día, la segregación espacial opera como fuente de una ciudad crispada, partida en dos o tres y donde una parte siempre se invisibiliza para la otra.

El texto de Juan Poblete, "Las fronteras internas en la ciudad de Santiago: Lemebel", acude a reflexiones de Saskia Sassen, Martín Barbero, José Luis Romero y García Canclini para buscar la espacialización de lo social en la obra de Lemebel y su representación de la ciudad de Santiago como experiencia vivida en el otro extremo. Mientras por un lado, el mal representa una reconstitución de lo social a partir del simulacro de libertad basado en el consumo, por el otro, se busca recuperar la densidad histórica de ciertos espacios neutralizados. Esto lo hace Lemebel, según Poblete, por medio de la conexión entre espacios y memorias concretas a través de la afectividad del cuerpo. En este sentido, resulta de interés la manera diversa como Opazo y Poblete leen la representación que hace Tomás Moulián de este periodo.

La sección o capítulo titulada "Niños jugando: barrios" agrupa textos de Rubí Carreño, Valeria de los Ríos y Bernardita Llanos. En todos ellos prima la representación del barrio ligado a la memoria y como también señala Magda Sepúlveda, a su destrucción. Rubí Carreño se detiene en la escuela de barrio, lugar sintomático de las capas medias, clase social siempre inexacta en su ambigüedad económica, que también aparece en los otros trabajos. Al analizar dos narraciones de diferentes países: Formas de volver a casa (2011) de Alejandro Zambra (chileno) y Ocio (2008) de Fabián Casas (argentino), que muestran vidas de barrio (como también lo hizo anteriormente José Leandro Urbina), la autora reconstruye la relación que tiene la memoria como reflexión sobre ciertos barrios (Maipú y Boedo), que aparentemente 
no tienen historia por lo nuevos o cuya historia se ha invisibilizado por los cambios que trae la ciudad neoliberal. Aunque el barrio de Casas tiene más "espesor cultural" que el Maipú de Zambra, en ambos textos -señala la crítica- se aprecia la unidad entre libros, canciones y amores de la barriada y la internacionalización en los sujetos del deseo de un hogar reconocible que se busca a sí mismo a través de la reconstrucción de una memoria minimalista.

En el texto de Valeria de los Ríos, se lee la imagen del Santiago construido en películas de Raúl Ruiz, Enrique Lihn (con Carlos Flores y Pedro Pablo Celedón) e Ignacio Agüero, en las últimas décadas del siglo XX. Consciente de sus diferencias, la autora recupera ciertas afinidades de los filmes: semificción los dos primeros (Retorno de un amateur de bibliotecas y Adiós a Tarzán), documental el último (Aqui se construye), especialmente el vínculo afectivo con el territorio de la infancia y el lugar central que ocupa la memoria. En todos los casos, el espectador debe ser activo y debe recuperar el cuestionamiento a la contingencia que se expresa en la actualización de las imágenes.

El otro texto del conglomerado barrial, lo constituye "La espacialización de la memoria en Nona Fernández y Carmen Castillo" de Bernardita Llanos, en el cual se exponen experiencias que se dejan fuera del discurso oficial, pero que están vinculadas a la identidad y a la memoria. Los textos que se revisan son la novela Mapocho (2002) de Nona Fernández y el documental Calle Santa Fe (2007) de Carmen Castillo que remarcan la relación ciudadana con el río y el barrio Bellavista en un caso y con la calle Santa Fe en el otro. En ambos discursos, dice la autora, la ciudad tradicional ha sido borrada, transformada y modernizada. Aunque se trata de dos experiencias totalmente diferentes -cuerpos maltratados y abusados en uno, lucha contra el olvido en el otro-, en ambas la recreación de los lugares de la distopía en la memoria sirve como reconocimiento del otro no visible, que así es resignificado y vuelve a fundarse.

Muy brevemente, revisaré los capítulos que siguen. "Trabajos en la vía: fuera del camino", como señala la editora, recoge la escritura académica sobre los marginales y los desplazados. Andrea Kottow recorre los inicios del siglo XX para dar cuenta de las "patologías urbanas en las urbes patógenas", focalizándose en El roto de Joaquín Edwards Bello, representante de los residuos de los discursos modernizadores y progresistas. Articula con gran coherencia la relación entre la dramatización médica de la infección y la carne degradada de los marginales del momento en la ficción naturalista. Malú Sierra recurre al texto Naciste pintada de Carmen Berenguer y a la producción fotográfica de Paz Errázuriz para mostrar cómo dos dispositivos vi- 
suales (el mapa y la fotografía) construyen una ciudad paralela casi invisible a los ojos del poder, como un "entre lugar" del cual el lector puede reapropiarse en su extrañeza. Lucía Guerra-Cuningham incursiona en la ciudad ajena representada por los escritores de origen mapuche (exiliados como Elicura Chihuailaf, ciudad desechada como en Leonel Lienlaf, o ciudad que margina y que es recobrada desde la subalternidad, como en David Añiñir y su Mapurbe). El trabajo que cierra este capítulo es de Allison Ramay y se refiere a la novela Desde el fogón de una casa de putas williche de Graciela Huinao, que a su juicio plantea una ciudadanía multicultural.

El capítulo 4 que se titula "Estamos grabando: urbanidades de mujer" recoge tres trabajos de diferente factura y énfasis, que se agrupan solamente en base a la diversidad de representaciones urbanas que se muestran a través de personajes femeninos en el caso de Blest Gana analizado por Alvaro Kaempfer y/o escritoras como Mistral en el caso de Elizabeth Horan y de Eltit, Maturana y Nona Fernández en el caso de María Inés Lagos. Kaempfer visualiza Durante la reconquista de Blest Gana, como un ejercicio de reelaboración de la ocupación de territorios, cuerpos y afectividades, como un intercambio objetual que sirve para vencer al rival. Como señala Magda Sepúlveda, implica la exclusión funeraria de la mujer del espacio de una realidad donde sólo es objeto de negociación. Horan construye el concepto de "clandestinidad" para mostrar, en un acucioso trabajo de investigación, la invisibilización de Gabriela Mistral en California, radicada en los márgenes y buscando alianzas heterogéneas y marginales. Ninguneo de la poeta en Chile, pero también en relación a sus cargos diplomáticos que, a su juicio, no la alienaron de la crítica persistente al sistema antidemocrático que existía en Chile con Gabriel González Videla. El trabajo de María Inés Lagos incursiona en la relación que se produce entre ciudad y mujer, en las narraciones de Diamela Eltit (Jamás el fuego nunca), Andrea Maturana ((Des) encuentros (des)esperados) y Nona Fernández (El cielo). Los textos, según lo señala la autora del trabajo, exploran interioridades y subjetividades en vivo, enfrentadas al mundo de la ciudad buscando su identidad individual.

El último capítulo, "Sitio eriazo, fantasmagorías urbanas", tal vez el más heterogéneo de todos, ya que se refiere a cine, artes visuales y narrativa, reúne trabajos de David William Foster, Alejandra Wolff y Malva Marina Vásquez. Foster escribe sobre Acta general de Chile de Miguel Littin, un informe fílmico sobre la sociedad bajo la dictadura con una cámara infiltrada y un Littin clandestino. El autor describe las diversas historias que relata Littin, especialmente los testimonios de la primera parte que instalan la falsa legitimidad de la dictadura así como las fantasmagóricas imágenes 
de lugares transformados o deshabitados por el proyecto neoliberal. Por su parte, el trabajo de Alejandra Wolff sobre los artistas plásticos de los '90, se detiene en los embates de la memoria urbana, como señala su título, que permean las obras de tres artistas. Ellos son: Carlos Silva, en quien la ciudad aparece bajo el vestigio de lo anormal, lo no oficial, el exceso y su degeneración, como en el caso de los edificios de caracoles; Carolina Illanes, que muestra un transeúnte que deconstruye sus trayectos para anotar una ciudad que se muestra en sus intersticios cotidianos, elaborando un catastro de fachadas, mostrando casonas venidas a menos y los proyectos de modernización truncos y Leonardo Portus, artista autodidacta que elabora mapas de sus recorridos urbanos para hacer un rescate patrimonial de las fachadas de edificios desmantelados por la dictadura. Como señala Wolff, son artistas que con diversos formatos plásticos y fotográficos hacen una reflexión crítica al rescatar lugares venidos a menos por una historia reiterada de simulacros de modernización. El último trabajo del libro es una reflexión de Malva Marina Vásquez sobre dos novelas de Nona Fernández (la autora más citada en este libro). En su texto, la académica analiza la relación entre la memoria urbana y las ciudadanías abyectas, en donde a contrapelo del discurso oficial de la nación, se realiza una práctica de resistencia por protagonistas disidentes que se oponen a los consensos del programa nacional neoliberal.

Quiero finalmente resumir mi opinión ya expresada anteriormente. Se trata de un libro que como conjunto aporta representaciones relevantes sobre los imaginarios que la ciudad crea, recrea y hace vivir a sus habitantes, especialmente a aquellos que habitan su exclusión, su marginalidad, su segregación, su prohibición, su expulsión al vacío, pero también a aquellos que se resisten a desaparecer y buscan una nueva pertenencia. En este sentido, el arte, la literatura, el cine, según nos muestran estos críticos y críticas, nos ayuda a recobrar la memoria de lo que fuimos y de lo que somos, para que ni los oropeles transnacionales ni las locuras consumistas nos tapen para siempre y la ciudad que perdimos nos devuelva nuestra humanidad. 